History

Education

Research

Journal
Wilschut, A. and Schiphorst, K. (2019), '"One has to take leave as much as possible of one's own standards and values": Improving and measuring historical empathy and perspective reconstruction'. History Education Research Journal, 16 (1): 74-87. DOI https://doi.org/10.18546/HERJ.16.1.07

\title{
'One has to take leave as much as possible of one's own standards and values': Improving and measuring historical empathy and perspective reconstruction
}

\author{
Arie Wilschut* and Koen Schiphorst - Amsterdam University of Applied \\ Sciences, the Netherlands
}

\begin{abstract}
Historical empathy or perspective taking has been a bone of contention in studies on history teaching, and the concept remains ill-defined. This may have been caused by a lack of theoretical reflection, as well as by the application of diverse research methods: a more cognitive or 'rational' explanation of the concept has often been substantiated by quantitative methods, while the more affective dimension has regularly been explored by qualitative methods. In this contribution, we trace some theoretical backgrounds of 'empathy' in historical theory as well as social psychology. Then we present a mixed-methods study employing a quantitative standardized measure developed in previous research in Germany and the Netherlands, as well as qualitative measurements. Results suggest that while, on the one hand, the standardized measure proved to be unreliable, both quantitative and qualitative methods can shed more light on what is going on when students try to take the point of view of historical agents. Based on theory, as well as our explorations, our conclusion is that empathy or perspective taking should be seen as a cognitive operation. We propose to see the reconstruction of historical perspectives as a specific element of historical explanation, not as a separate concept of 'historical empathy' or 'historical perspective taking'.
\end{abstract}

Keywords: historical empathy; historical explanation; historical perspective; historical thinking; the Netherlands

\section{Introduction}

The reconstruction of the perspectives of historical agents in order to better understand and explain their utterances and actions is generally regarded as an important element in historical thinking as it should be taught in schools (Barton and Levstik, 2004: 208; Cunningham, 2009; Downey, 1995; Foster, 1999; Lee and Ashby, 2001; Seixas and Morton, 2013: 138; Shemilt, 1984). A competence or propensity that is often connected to this reconstruction activity is 'historical empathy' - a term referring to the inclination or ability to imagine how people in the past must have thought or felt, given their perceptions of reality, their convictions and beliefs (Dulberg, 2002; Lévesque, 2008: 142; Yilmaz, 2007). Empathy is also often given the broader meaning of understanding or explaining human actions and thoughts in the past, in which case it virtually coincides with reconstruction of historical perspectives.

The discussion about historical empathy in history education has been going on since the 1980s (Boddington, 1980; Stockley, 1983; Knight, 1989) and continues 
(Endacott and Brooks, 2013; Huijgen et al., 2017; Rantala et al., 2016; Virta and Kouki, 2014) without consensus being reached about the exact meaning of the concept or its correct application in history teaching. It is striking that the educational debate hardly refers to the debate about historical explanation in historical theory, nor to social psychology about empathy and perspective taking, with the notable exception of Nilsen (2016), who explicitly connects historical understanding to social psychology. In our theoretical framework, we try to make some connections between history education and historical and psychological theory.

The confusion about the concept may also have been caused by the fact that very diverse research methods have been applied. While the majority of history education researchers draw upon both qualitative and quantitative research methods, as appropriate, some research has been exclusively qualitative (for example, Brooks, 2008; Endacott, 2014), while others have employed purely quantitative methods (for example, Hartmann and Hasselhorn, 2008; Huijgen et al., 2014). Qualitative studies usually result in accentuating the 'affective' component of 'empathy', while quantitative studies show an inclination to stress the 'rational' and 'cognitive' features. Therefore, we present a study based on mixed methods (Kelle, 2006), which may shed light on the conceptual problem of historical perspective reconstruction. By means of quantitative measurements we want to explore if and how progress in the skill of historical perspective reconstruction can be determined, while qualitative exploration can shed light on how students experience their activities in this respect, and whether these experiences point towards a more affective or more cognitive interpretation of the concept.

\section{Theoretical framework}

Theories on historical explanations in historical theory, as well as social-psychological theories on empathy and perspective taking, may be employed to clarify the concept of historical perspective reconstruction in history education. For reasons of space, only very sketchy outlines of these theories can be presented here.

A major controversy in historical theory has been the one between a hermeneutic and a positivist deductive-nomological approach to historical explanations. An important scholar representing the hermeneutic point of view was the German philosopher Wilhelm Dilthey (1833-1911), who argued that a distinction should be made between explanation in the natural sciences and in the human sciences, because the latter not only deal with visible things, but also with their meaning, which cannot be observed directly (Dilthey and Jameson, 1972). Understanding of meanings can only arise by means of interpretation (verstehen), based on a shared humanity of people in the past and in the present. The problem here is how to understand something alien, which is not shared, and which is arguably the object of the historian wishing to understand the 'strangeness' of the past. Dilthey was aware of this, but still believed that interpretation was the key, because however strangely people in the past thought and acted, nothing 'explainable' about them could be totally alien:

Interpretation would be impossible if the expressions of life [Lebensäusserungen] were completely alien. It would be unnecessary if there was nothing alien to them. So interpretation lies between these two extremes. It is required wherever there is something alien which should be turned into familiar by means of the art of interpretation. (Dilthey, 1981: 278-9 [our translation]) 
An important auxiliary for constructing correct interpretations is, according to hermeneutic theory, a thorough knowledge of context: the individual can be understood by means of reference to the 'whole', while the whole can only be understood in the way it is built up by its individual parts (Skinner, 1975). It is this cyclic character of hermeneutics that causes the concept to be contested by its critics (Tully, 1988).

A similar position to Dilthey's was taken by the British philosopher Robin Collingwood (1889-1943), who stated that historians explain the past by re-enacting past thoughts in their own minds, imagining past realities as they must have appeared to historical agents (Collingwood, 1973: 282-3). His theory probably influenced the anglophone debate on empathy in history teaching a great deal (see, for example, Stockley, 1983; Shemilt, 1984; Lee et al., 1997).

In opposition to hermeneutic philosophers, Carl Hempel (1905-97) took the view that there is only one form of science: the positivist, empiricist deductive-nomological way of thinking of the natural sciences (Hempel, 1942). Unless historical explanations could refer to general laws (whenever A happens, B is the consequence), they would be no scientific explanations at all (ibid.: 37-8). Hermeneutic understanding could at most be a heuristic device, but not provide a satisfactory explanation (ibid.: 44).

Hempel's radical dismissal of hermeneutics gave rise to much debate, because the scientific status of history was at stake. Very few historical explanations could be based on general laws, because human behaviour is often unpredictable (Dray, 1957: 7-13). The solution offered by William Dray (1921-2009) - the model of 'rational understanding' - seemed to correspond most closely to what historians actually do. They describe: (1) the factual situation as it was perceived by a historical agent; (2) the probable consequences (as foreseen by the agent) of a range of actions that the agent believed to be feasible options; and (3) the goals the agent wanted to achieve. From a combination of these three, historians deduce rationally the explanation for the choices the agent made (Dray, 1989: 18). Thus, while general laws were dismissed, rational deduction was retained, as well as empirical facts, without resorting to something as vague as empathically trying to feel and think like people in the past. Strikingly enough, almost exactly this model of rational understanding was presented by history educator Peter Lee (1984: 90), without reference to Dray.

Several issues raised in the debate on historical empathy in history education can be related to the debate in historical theory. The idea of 'entering into the minds' of people in the past, first dismissed in the discussion as something that does not represent empathy (Foster, 1999; Knight, 1989; Lee and Ashby, 2001; Shemilt, 1984; Stockley, 1983), and then miraculously revived as something that is essential to empathy (Brooks, 2008; Endacott, 2010; Endacott and Brooks, 2013; Harris and Foreman-Peck, 2004; Kohlmeier, 2006), can easily be related to the debate about hermeneutics. The problem of 'hermeneutic naïveté' (Megill, 1989: 636), is assuming that the personality of the researcher plays no role in his interpretation, thus guaranteeing the 'objectivity' of the result of a hermeneutic procedure. In fact, the opposite is the case, and this also applies to history education. While some researchers argue that comparing one's own similar experiences to those of people in the past positively influences historical understanding (Endacott, 2014; Kohlmeier, 2006), others state that it may lead to 'mind-numbing presentism that reads the present onto the past' (Wineburg, 1999: 493). Some empirical results indicate that students do 'fill the gaps' with presentist imagination, especially in cases in which they are asked to 'imagine themselves in the past' (Brooks, 2008; Cunningham, 2003: 260; De Leur et al., 2017; Huijgen et al., 2017; Rantala, 2011). In this context, it is also frequently being stressed that students should respect the differences between present and past, and the distance that separates us 
from people of bygone days (Downey, 1995; Foster, 1999; Phillips, 2004; Shemilt, 1984; Wineburg, 1999). However, it is difficult to see how this could be reconciled with active engagement of one's own experiences when trying to explain people in the past.

Context is another aspect of hermeneutics that can be applied to the discussion. Research in history education has shown that it is often a lack of contextual knowledge that impedes correct reconstructions of historical perspectives by students (Downey, 1995; Foster, 1999; Rantala, 2011). Especially Berti et al. (2009) have shown that the model of progression in historical empathy that Lee et al. had been building up, based on the 'disposition' for empathy or the ability of students to empathize in different stages of development (Lee et al., 1997; Lee and Ashby, 2001), could, in fact, be attributed to the availability or lack of enough background information understandable to students.

Social psychology shows that social perspective taking should be interpreted first and foremost as an element of face-to-face interaction between people in the present, referring to things such as conflict resolution (Gehlbach, 2004a). It appears to be correlated only very weakly with the ability to reconstruct the perspectives of historical agents (Gehlbach, 2004b). The essential element of historical distance, of 'strangeness' of past thoughts and actions, is no part of it. This justifies Knight's (1989: 44) critical statement on historical empathy: 'Any useful psychological findings about how people empathize with others who are in a reciprocal relationship with them are of little use to the educationalist interested in how to promote understandings of those who are in no such relationship'.

Psychological theory may also be related to the question of whether we are talking about a purely cognitive ability, or (also) about an affective inclination or disposition. The affective element obviously plays an important role in social perspective taking (Hoffman, 2000: 4). However, the history educators Barton and Levstik (2004: 229-41) introduced the element of 'caring' in their theory of empathy, followed by others stressing the importance of the affective component (Brooks, 2011; Endacott, 2010). Endacott and Brooks (2013: 43) state that students should 'affectively connect' to past agents to be able to understand their seemingly irrational behaviour, which, if judged only rationally, would lead to ill-founded condescending attitudes. This seems to be an erroneous application of social-psychological theory. While in everyday human interaction, affective connections do play a role, understanding 'strange' actions and thoughts in the past is not a matter of sharing feelings, but - on the contrary a matter of rational use of the available contextual information that makes strange actions understandable and justifiable. Affective reactions to past behaviour, rather than cognitive understanding, probably give rise to presentist and condescending attitudes that we wish to avoid. As Berti et al. (2009) have shown, the availability of adequate background information is decisive.

Theories about the affective component of historical empathy may also have been derived from the motivational aspect of social perspective taking (Gehlbach, 2004a). Taking the perspective of someone else is not only a matter of ability, but also of propensity or motivation to do so, which is indeed a matter of feeling rather than cognitive deliberation. However, Gehlbach (ibid.: 211) points out that the result of a willingness, whether or not propelled by affective considerations, may either be a correct or an incorrect estimate of someone else's thoughts and feelings. The risk of a wrong estimate is considerable, because empathy is inherently biased by one's own thoughts and feelings (Bloom, 2016: 31, 68, 108). Incorrect estimations are mostly due to a lack of correct information, and this is also the case in daily interactions with fellow human beings. Transferred to the educational context, we may conclude that the inclination to reconstruct historical perspectives could be seen as the motivation 
to study history seriously, or, in more general terms: the motivation to learn, which is indeed a partly affective endeavour (Immordino-Yang and Damasio, 2007). But this is not restricted to perspective reconstruction in history, or especially related to it. If mistakes are made in the correct estimation of thoughts and feelings of people in the past, it is mostly due to a lack of, or defective study of, contextual information.

Lévesque (2008: 163-8) more or less summarizes the available research in a threestage model of teaching 'historical empathy': imagining, contextualizing and judging. Imagining is a necessary first step to create a lively representation of the historical situation for students to be able to picture it and to raise questions. Contextualization is the backbone of understanding the situation, as argued above. Judging is advised by Lévesque because, given the fact that students somehow always implicitly have some judgement about 'strange' things in the past, it seems better to make such judging processes explicit in order to relate them in orderly ways to the available contextual information.

Summing up, explaining utterances and actions of past agents is mostly a matter of rational understanding, as described by Dray (1957). Essential to the correct explanation of strange past utterances and behaviours is the availability of contextual information and the motivation of students to take this into account. If historical context is lacking, or if students fail to study it seriously, this often results in 'filling the gaps' by presentist notions. This explains why Hartmann and Hasselhorn (2008), in their search for a standardized measure for historical perspective taking, found a reliable bipolar component representing 'contextualization' on the one end and 'present oriented perspective taking' on the other. Next to these two, they discerned taking into account 'the role of the historical actor', which focuses specifically on the personal situation of an agent. This could be seen as an in-between position between presentist judgements and contextualized judgements, because it elicits bringing in one's own perspective as well as context: 'if I were him in that situation, I would ...'. This model, which has also been applied by Huijgen et al. $(2014,2017)$, has been used as one of the quantitative measures in the empirical study presented below.

\section{Method}

We designed a small-scale explorative intervention study to find out whether students' abilities to reconstruct historical perspectives could be improved, and whether Hartmann and Hasselhorn's (2008) 'standardized measure' could be used to demonstrate such improvements. We also wanted to know how students reflected upon their activities of perspective reconstruction, and whether they experienced these mainly as something cognitive or something affective. Therefore, we used a mixed methods pre-/post-test design with an intervention group and a comparison group.

\section{Participants}

Participants in the intervention group and comparison group were 36 and 33 tenthgrade students (age 15-16) respectively from one secondary school located near Utrecht in the Netherlands in a white, middle-class neighbourhood. The school provides general secondary education (HAVO) and pre-university education (VWO), that is, the middle and higher streams of Dutch secondary education. As history is a compulsory subject in the Netherlands up to the ninth grade (age 14-15), these students had opted for history as one of their final examination subjects. Students from this school perform above average in the national state examinations. Both the intervention and comparison groups contained proportionally equal numbers of HAVO 
and VWO students. Because they were parallel groups in the school, their composition and performances were comparable. Measurements on our pre-test revealed no significant differences between the intervention group and the comparison group.

\section{Intervention}

The intervention was based on Lévesque's (2008: 163-8) three-stage model of historical empathy. Students studied the thoughts and acts of two controversial historical persons: Maximilien Robespierre's radical application of revolutionary principles and Thomas Jefferson's debatable conduct as a slave-owner, each during three lessons of 50 minutes each (a total of six lessons). In each of the two cases, students' imagining of the situation was first stimulated by means of audiovisuals, play-reading and primary sources. Then, contextual information was provided by reiterating the main outlines of the period (which had been studied by students before in their general courses on history) and studying further primary and secondary sources representing multiple perspectives. Finally, judging the past was stimulated by whole-class discussions, followed by having students write short essays on their judgement of the conduct of these historical agents, stimulating them to make the values of the period and presentday values explicit. An instruction card was produced that expounded the three stages of imagining, contextualizing and judging, each with their focus questions:

- Stage 1, imagining: In which period is this happening? What do I know about this period? What comes to my mind when imagining this period?

- Stage 2, contextualizing: What were the backgrounds of the person I am dealing with? What were his personal beliefs and convictions? In what kind of society did this person live and what were the dominant values, beliefs and opinions?

- Stage 3, judging: What are my personal perceptions of this historical topic and how do they influence my judgement? What differences are there between the standards and values today and those of this period? Am I able to judge the conduct of this person, balancing all information? If so, what would my judgement be?

\section{Research questions}

Because we were interested to know whether perspective reconstruction in history lessons can be improved, and whether a possible improvement can be assessed by means of quantitative and qualitative measures, we formulated the following research questions:

1. Can a possible improvement of historical perspective reconstruction as a result of an intervention based on Lévesque's (2008: 163-8) three-stage model be assessed effectively by means of Hartmann and Hasselhorn's (2008) standardized measure?

2. Are the results of quantitative measurements confirmed or contradicted by the results of qualitative methods to gauge improvements in historical perspective reconstruction?

3. How did students reflect on their attempts to improve their historical perspective reconstruction?

\section{Measurements}

In order to assess a possible improvement in the ability of the intervention group students to reconstruct historical perspectives, we designed two adapted versions 
of Hartmann and Hasselhorn's (2008) standardized measure. This instrument consists of a description of the situation of a person in the past, followed by a choice the person should make (in Hartmann and Hasselhorn's original case: is the person going to vote for Hitler or not?). The student then has to make up his or her mind about nine statements, three of which represent a 'presentist' motivated choice, three a choice motivated specifically from the situation of the agent, and three a choice motivated from the historical context in which the agent finds himself or herself. For each of the statements, students are asked to estimate whether or not it fits the situation of the agent on a four-point scale (varying from fits not at all to fits very well). Our adapted versions of this instrument described the situation of a nineteenth-century factory girl, Anna, who is faced with the dilemma of joining a strike or not, and the situation of an eleventh-century French farmer, Joseph, who has to make up his mind whether he will join a crusade. We deliberately chose two situations different from the ones studied during the intervention, because we wanted to see the results in terms of perspective reconstruction as such, not in terms of perspective reconstruction in a specific context that had been studied, in which case reproduction of specific knowledge could also play a role. We chose two different situations for the pre-test and post-test because we wanted to avoid the test/re-test effect, and because we wanted to check if Hartmann and Hasselhorn's (2008) measurement is in fact 'standard', meaning irrespective of the historical content to which it is being applied.

Example statements of the three kinds described above are:

Presentist: (1) Anna should not join the strike. She will be better off in the factory in order to get a good training. With a better education she will have a much better chance to get a good job, and that will change her living and working conditions.

(2) Peter the Hermit says it is 'God's will' to fight against the 'infidels' in the east. Since there is no way to prove that Peter is right, Joseph will not join.

Situation of agent: (1) One of Anna's friends is planning to strike. Her situation is as bad as Anna's and her family also has a hard time. If Anna is to show solidarity, she has to decide to join the strike.

(2) Joseph's youngest daughter is seriously ill. Joseph feels he has to make a sacrifice to God, so that the poor child will be cured. This will influence his decision to go on a crusade.

Context: (1) The chances are that Anna will lose her job if she strikes. There is great unemployment in her city. Every week, poor farmers from the countryside pour into the city in search of work.

(2) Joseph is an extremely religious man: if the supreme leader of the Church makes an appeal to fight for Christianity, it is his duty to respond to it.

The eighteen items were presented to two experts in random order, with a short description of the categories 'presentist', 'situation of agent' and 'context'. The experts assigned them to the correct categories with an agreement of 89 per cent.

The factory girl case was used as pre-test and the crusade case was used as posttest. Our descriptions of the situations of historical agents were somewhat lengthier (about 400 words) than the one provided in Hartmann and Hasselhorn's (2008) original case (about 300 words), in order to be able to provide enough contextual information. The instruments were applied simultaneously in the intervention group 
and the comparison group before and after the intervention period, during which the comparison group had received 'business as usual' history education.

The second instrument was a short essay assignment added to the cases described above. Students were informed about the choices that Anna and Joseph eventually made, and then asked to describe how they evaluated this decision: 'Joseph finally decided to leave with his family to go on a crusade. What do you think of this? Do you agree or disagree? Give as many arguments as possible to substantiate your answer.' In order not to influence the first quantitative measurement, this qualitative assignment was only given to the students after they had handed in their quantitative scores, but during the same session, which ensured that they could still envisage the historical situation well. This instrument was applied in the intervention group as well as in the comparison group.

The third instrument was a so-called 'learner report' (De Groot, 1974), an instrument with open questions that incite students to reflect upon their learning process. Our instrument contained these questions:

- The most important thing I learned in these lessons was ...

- I learned this mainly through ...

- Judging people and situations in the past is often awkward, because ...

- If you wish to empathize with people in the past, you always have to consider ...

- I have found it useful/not useful to learn about how to reason about the past instead of just learning facts about the past, because ...

- After these lessons, I will probably make use of the three-stages model frequently/ sometimes/never, because ...

This instrument was only used in the intervention group, because the comparison group had no specific learning process to reflect upon.

\section{Data processing}

The options on the quantitative scales of Instrument 1 were assigned the values 0 to 3 in the categories 'context' and 'situation of agent': 0 for 'fits not at all', and 3 for 'fits very well'. In the category 'presentist', a reverse scoring was applied, because viewing a presentist consideration as fitting is proof of bad historical perspective reconstruction. This implies that total scores for the instrument could vary between 0 and 27, representing minimal and maximal performance in historical perspective reconstruction. Sub-scores for the three subscales could vary between 0 and 9 . The validity and reliability of the instruments were determined by means of a principal component analysis, and calculating the Cronbach's alphas. As these data answer one of our research questions, we present the results in the 'Findings' section.

The textual data from Instrument 2 were scored quantitatively as well as analysed qualitatively. We searched for elements of 'rational judgement of the past' as described in Table 1. The number of elements found was scored for each text. The number of words written per text was counted.

Qualitative analysis of the data consisted of searching for the kind of arguments given by students. We mainly looked for differences in the kind of arguments used in the intervention and comparison groups. In addition, we looked for the words that were used to describe situations and persons, and whether they fitted with students' judgement.

The data from the learner reports were analysed qualitatively. We looked for the kind of arguments with which students substantiated their views on whether or not it 
is useful to try to reconstruct past perspectives and whether or not the three-stage model was experienced as useful.

Table 1: Scoring categories for written assignments (Instrument 2)

\begin{tabular}{ll}
\hline Category & Example sentences \\
\hline $\begin{array}{l}\text { Student regards historical agent as a } \\
\text { rationally acting person }\end{array}$ & $\begin{array}{l}\text { 'This job is the only means of existence for } \\
\text { her and her family, why would she risk losing }\end{array}$ \\
$\begin{array}{ll}\text { Student identifies him-/herself as a historical l by going on strike? It is a sensible choice.' } \\
\text { agent who imagines the situation }\end{array}$ & $\begin{array}{l}\text { 'I think that if I were religious in that period, } \\
\text { I would as a poor man also be susceptible to } \\
\text { lies.' }\end{array}$ \\
$\begin{array}{ll}\text { The historical agent's actions are judged from } \\
\text { the context of the historical period }\end{array}$ & $\begin{array}{l}\text { 'The factory boss can still live off his reserves } \\
\text { for some time, but someone like Anna }\end{array}$ \\
\hline
\end{tabular}

\section{Findings}

Principal component analyses executed for the pre- and post-test quantitative instruments based on eigenvalues larger than 1 with varimax rotation and Kaiser normalization revealed in both cases four factors explaining 61.6 per cent (pre-test) and 63.0 per cent (post-test) of variance. These appeared to coincide in no way with the subcategories 'presentist', 'situation of agent' and 'context'. Each contained variables from two or three different subscales in either of the tests. However, it could be argued that even if no subscales were detected, the sum scores represented in fact one factor, because 'presentist' and 'context' complement each other as opposites, while 'situation of agent' could also be seen as a kind of historical context. The subscales appearing to be non-existent, we only calculated Cronbach's alphas for the complete instruments, which were 0.22 for the pre-test and 0.50 for the post-test.

These are unacceptably low values. Therefore, the adapted versions of Hartmann and Hasselhorn's (2008) standardized measure proved to be unreliable. This conclusion is underlined if we analyse the total scores for the pre- and posttests for both groups, as presented in Table 2. We detected no statistically significant differences, neither between the two groups on the pre-test $(F=0.098, p=0.654)$ nor on the post-test $(F=2.325, p=0.647)$, nor between pre- and post-test within either of the groups (respectively: $t=1.34, p=0.189$ and $t=1.26, p=0.215$ ). Therefore, it has proven impossible to measure differences in the ability of students to reconstruct historical perspectives, between groups or before and after the intervention.

Table 2: Quantitative assessments of historical perspective reconstruction (Instrument 1)

\begin{tabular}{ll}
\hline Group & Score \\
\hline Comparison group & Pre-test 17.0 \\
& Post-test 18.0 \\
Intervention group & Pre-test 17.5 \\
& Post-test 18.3 \\
\hline
\end{tabular}


Quantitative scoring of the numbers of elements of 'rational judgement of the past' in the students' written judgements of the historical agents' decisions revealed the totals represented in Table 3. There appeared to be no significant difference between pre- and post-test in the comparison group ( $t=0.000, p=1.000)$, nor in the intervention group ( $t=1.711, p=0.096$ ), although in this case, the $t$ - and $p$-values were such that this suggests a 'trend'. The difference between the groups appeared to be not significant at the pre-test $(F=0.462, p=0.134)$, but at the post-test it was significant $(F=0.333$, $p=0.011)$. At the pre-test, the intervention group wrote 79 words on average and the comparison group 69 words. At the post-test these averages were 84 and 53 words respectively. The intervention group wrote longer answers after the intervention, thus probably adding more nuance to their judgements. All of this suggests that the intervention group's level of historical perspective reconstruction had improved, while in the comparison group it had remained more or less the same.

Table 3: Elements of rational judgement of the past in students' written assessments (Instrument 2)

\begin{tabular}{lllll}
\hline & \multicolumn{2}{l}{ Intervention group } & \multicolumn{2}{l}{ Comparison group } \\
& $\mathrm{N}=36$ & & $\mathrm{~N}=33$ & \\
\hline TOTAL & pre-test & post-test & pre-test & post-test \\
\hline & 52 & 62 & 40 & 38 \\
\hline
\end{tabular}

Looking at qualitative aspects of the students' answers, a difference between the groups was the extent to which reasoning showed characteristics of 'superiority of the present', which occurred to a greater extent in the comparison group than in the intervention group. For example: 'I find it very strange that people risk their lives for someone they do not even know'. In the intervention group, the context of the historical period was taken more into account. For example: 'I would not go, but Joseph was strictly religious - not me, so I would not use that as a motive, but in his case chances are that he saw it as an extra encouragement.' Looking at the kind of words used to describe situations and people, the comparison group more often used words such as 'strange', 'ridiculous' or 'incomprehensible' at their post-test. In both the pre- and post-test, almost all students argued from the personal circumstances of the agent, in which cases it seemed as if they were reasoning from their own presentday perspective. For example: 'Anna and her family are in a bad condition already, if she also loses her job because of the strike, she does not have anything anymore.' And in the post-test: 'I would not go because of the sick daughter', and: 'He put his family in insecurity, so I think it's a wrong choice'. Reasoning from personal circumstances of the agent therefore seems to be no guarantee for a genuine historical point of view.

From the learner reports, it was obvious that students experienced the assignments to reconstruct perspectives of historical agents as a difficult cognitive endeavour. For example: 'Understanding a person from history can be very difficult, because you have to distance yourself as much as possible from your own standards and values.' And: 'You have to imagine a different era and consider whether there was freedom, what position everyone had, etc. Our experiences now are just very different.' All students were able to report about the intervention process, with varying points of view. On the question of whether they would use the three-stage model in the future, some commented that they did not see this happening soon, while one 
student reported: 'I will use perspective reconstruction and judging a bit more often than usual, but I myself had the idea that I had already mastered it.'

A considerable number of students, however, wrote that using the three stage model would facilitate proper judgement and that they expected to score better results on tests by using it. This gain was seen as a cognitive advantage, for example: 'You don't just learn the facts, but you also understand events much better', and 'I think this can be used outside history, it teaches you to be more critical'. Elaborating on their learning processes, students frequently mentioned the three-stage model, as well as the assignments on Robespierre and Jefferson: 'The teacher instructions let us experience what this is about, but we mainly learned by doing the various exercises', and 'I learned by the short texts about people who had to make an important choice. Then you really had to think about what was going on in their minds.' Students more than once indicated that they enjoyed learning about this aspect of history: 'History is quite factual, that's why I like to learn how to view those facts correctly so that I can get an impression of what really happened', and 'I enjoyed seeing something from someone else's perspective'. The affective component here is the enjoyment of better understanding, not the feeling for other people. For students, reconstructing past perspectives is a cognitive procedure, which is useful for better insights into the past and fostering critical thinking.

\section{Conclusion and discussion}

It has proved impossible to measure shifts in historical perspective reconstruction by means of adapted versions of Hartmann and Hasselhorn's (2008) quantitative 'standardized measure'. Admittedly, the small size of our samples made it difficult to apply quantitative methods, and perhaps the case of a nineteenth-century factory girl was significantly different from the one about a prospective crusader. Even so, we applied the three categories discerned by Hartmann and Hasselhorn (ibid.) in both cases, but were unable to retrieve them in either case separately by means of principal component analysis. The reliability of either instrument proved to be unacceptably low. Total results of both tests suggested that nothing changed, while our other findings suggest that in fact something did change in the intervention group's dealing with historical perspective reconstruction.

In previous research, it has also proved difficult to produce adapted versions of Hartmann and Hasselhorn's'standardized measure' (Huijgen etal., 2014). That contextual knowledge plays a decisive role here, as we have argued in our theoretical framework, is underlined by a closer study of Hartmann and Hasselhorn's instrument. In their case, a young man in Germany in 1930 had to decide whether or not to vote for Hitler. All considerations in the instrument not to vote for Hitler represented the 'presentist' category, while all considerations to vote for Hitler represented the 'contextual' category. The considerations representing 'the situation of the agent' implied voting for 'an anti-democratic party, but not necessarily the NSDAP'. That the categories 'presentist' and 'contextual' neatly fitted into one line with two extremes, is therefore not surprising, because one either votes for Hitler or not. Besides, from their general contextual knowledge about Hitler, students must have known that a large proportion of Germans in the 1930s voted for Hitler, which made the 'contextual' choices more likely. In our examples, the contextual knowledge was less self-evident and the choices whether or not to strike or go on a crusade were mixed in the 'presentist', 'contextual' and 'situation of agent' categories. After all, in the nineteenth century, some people decided to strike, and others decided not to strike, and in the Middle Ages, some 
people went on a crusade, while others did not. In these circumstances, Hartmann and Hasselhorn's model does not hold. So there are reasons to believe that theirs is not a 'standardized measure' for assessing historical perspective reconstruction; more so, if we take into account that application of their quantitative instrument suggests that the levels of historical empathy with senior secondary students is generally adequate (Hartmann and Hasselhorn, 2008; Huijgen et al., 2014), while other research based on qualitative methods signals serious deficiencies (Rantala, 2011; Rantala et al., 2016).

This does not exclude that quantitative methods can be applied. Our admittedly rather crude - method of counting instances of rational judgement in the students' evaluations of the historical agents' decisions suggested some improvement in the intervention group, while the comparison group more or less remained the same. This impression was underlined and nuanced by our qualitative data. Therefore, this combination of quantitative and qualitative methods (Kelle, 2006) suggests that Hartmann and Hasselhorn's (2008) implementation of the construct 'historical perspective taking' is not satisfactory, and that the three elements of 'rational understanding' that we employed in our second instrument might be a useful starting point for further research.

Our qualitative data gave more nuance to the impressions generated by the numbers of 'rational understanding' elements that students included in their judgements of historical agents' decisions. From the learner reports, it is safe to conclude that most students in the intervention group thought they had learned something worthwhile that could make history more interesting and understandable. Another suggestion from these reports is that students did not consider the practice of historical perspective reconstruction as something affective, but rather as a demanding cognitive operation.

Based on theoretical considerations as well as our empirical findings, we propose to see the reconstruction of historical perspectives as a specific element of historical explanation, not as a separate concept of 'historical empathy' or 'historical perspective taking'. We have therefore preferred the term 'historical perspective reconstruction' in this paper instead of 'historical perspective taking'. There are a number of important disadvantages in trying to empathically 'take' the perspective of some historical agent. Empathy is biased, even in interactions in the present, implying that we inadvertently try to impose our own assumptions and ideas on those of others, and that we have personal preferences about those with whom we wish to empathize and those with whom we do not wish to do so (Bloom, 2016: 70, 108). Nilsen (2016) has demonstrated that the inclination to empathize with victims in history is considerably stronger than the inclination to empathize with perpetrators, more so in cases that are more recent than in distant historical cases. All of this indicates that assignments to 'put oneself into the shoes' of historical agents might be disadvantageous to correct historical understanding.

\section{Notes on the contributors}

Arie Wilschut is a historian, and a professor of social studies education at Amsterdam University of Applied Sciences (the Netherlands). He has published nationally and internationally about teaching history, and has acted as an editor of two volumes in the series International Review of History Education. He was one of the originators of a new curriculum for history education in the Netherlands based on ten associative eras.

Koen Schiphorst is a history teacher at the Herman Jordan Lyceum in Zeist (the Netherlands), a school for general secondary education. He acquired a master's 
degree in teaching history at Amsterdam University of Applied Sciences. His master's thesis focused on the concept of historical empathy. The empirical data for this study were generated in an experiment conducted at his school.

\section{References}

Barton, K.C. and Levstik, L.S. (2004) Teaching History for the Common Good. Mahwah, NJ: Lawrence Erlbaum Associates.

Berti, A.E., Baldin, I. and Toneatti, L. (2009) 'Empathy in history: Understanding a past institution (ordeal) in children and young adults when description and rationale are provided'. Contemporary Educational Psychology, 34 (4), 278-88.

Bloom, P. (2016) Against Empathy: The case for rational compassion. London: The Bodley Head.

Boddington, T. (1980) 'Empathy and the teaching of history'. British Journal of Educational Studies, 28 (1), 13-19.

Brooks, S. (2008) 'Displaying historical empathy: What impact can a writing assignment have?'. Social Studies Research and Practice, 3 (2), 130-46.

Brooks, S. (2011) 'Historical empathy as perspective recognition and care in one secondary social studies classroom'. Theory and Research in Social Education, 39 (2), 166-202.

Collingwood, R.G. (1973) The Idea of History. London: Oxford University Press.

Cunningham, D.L. (2003) 'Professional Practice and Perspectives in the Teaching of Historical Empathy'. Unpublished PhD thesis, University of Oxford.

Cunningham, D.L. (2009) 'An empirical framework for understanding how teachers conceptualize and cultivate historical empathy in students'. Journal of Curriculum Studies, 41 (5), 679-709.

De Groot, A.D. (1974) 'The problem of evaluating national educational systems'. In Crombag, H.F. and De Gruijter, D.N. (eds) Contemporary Issues in Educational Testing. The Hague: Mouton, 9-27.

De Leur, T., Van Boxtel, C. and Wilschut, A. (2017) " I saw angry people and broken statues": Historical empathy in secondary history education'. British Journal of Educational Studies, 65 (3), 331-52.

Dilthey, W. (1981) Der Aufbau der geschichtlichen Welt in den Geisteswissenschaften. Frankfurt am Main: Suhrkamp.

Dilthey, W. and Jameson, F. (1972) 'The rise of hermeneutics'. New Literary History, 3 (2), 229-44.

Downey, M.T. (1995) 'Doing history in a fifth-grade classroom: Perspective taking and historical thinking'. Paper presented at the American Educational Research Association (AERA) Annual Meeting, San Francisco, 18-22 April 1995.

Dray, W.H. (1957) Laws and Explanation in History. London: Oxford University Press.

Dray, W.H. (1989) 'Singular hypotheticals and historical explanation'. In Dray, W.H. On History and Philosophers of History. Leiden: Brill, 13-36.

Dulberg, N. (2002) 'Engaging in history: Empathy and perspective-taking in children's historical thinking'. Paper presented at the American Educational Research Association (AERA) Annual Meeting, New Orleans, 1-5 April 2002.

Endacott, J.L. (2010) 'Reconsidering affective engagement in historical empathy'. Theory and Research in Social Education, 38 (1), 6-47.

Endacott, J.L. (2014) 'Negotiating the process of historical empathy'. Theory and Research in Social Education, 42 (1), 4-34.

Endacott, J. and Brooks, S. (2013) 'An updated theoretical and practical model for promoting historical empathy'. Social Studies Research and Practice, 8 (1), 41-58.

Foster, S. (1999) 'Using historical empathy to excite students about the study of history: Can you empathize with Neville Chamberlain?'. The Social Studies, 90 (1), 18-24.

Gehlbach, H. (2004a) 'A new perspective on perspective taking: A multidimensional approach to conceptualizing an aptitude'. Educational Psychology Review, 16 (3), 207-34.

Gehlbach, H. (2004b) 'Social perspective taking: A facilitating aptitude for conflict resolution, historical empathy, and social studies achievement'. Theory and Research in Social Education, 32 (1), 39-55.

Harris, R. and Foreman-Peck, L. (2004) '"Stepping into other peoples' shoes": Teaching and assessing empathy in the secondary history curriculum'. International Journal of Historical Learning, Teaching and Research, 4 (2), 98-111.

Hartmann, U. and Hasselhorn, M. (2008) 'Historical perspective taking: A standardized measure for an aspect of students' historical thinking'. Learning and Individual Differences, 18 (2), 264-70. 
Hempel, C.G. (1942) 'The function of general laws in history'. Journal of Philosophy, 39 (2), 35-48.

Hoffman, M.L. (2000) Empathy and Moral Development: Implications for caring and justice. Cambridge: Cambridge University Press.

Huijgen, T., Van Boxtel, C., Van de Grift, W. and Holthuis, P. (2014) 'Testing elementary and secondary school students' ability to perform historical perspective taking: The constructing of valid and reliable measure instruments'. European Journal of Psychology of Education, 29 (4), 653-72.

Huijgen, T., Van Boxtel, C., Van de Grift, W. and Holthuis, P. (2017) 'Toward historical perspective taking: Students' reasoning when contextualizing the actions of people in the past'. Theory and Research in Social Education, 45 (1), 110-44.

Immordino-Yang, M.H. and Damasio, A. (2007) 'We feel, therefore we learn: The relevance of affective and social neuroscience to education'. Mind, Brain, and Education, 1 (1), 3-10.

Kelle, U. (2006) 'Combining qualitative and quantitative methods in research practice: Purposes and advantages'. Qualitative Research in Psychology, 3 (4), 293-311.

Knight, P. (1989) 'Empathy: Concept, confusion and consequences in a national curriculum'. Oxford Review of Education, 15 (1), 41-53.

Kohlmeier, J. (2006) '"Couldn't she just leave?": The relationship between consistently using class discussions and the development of historical empathy in a 9th grade world history course'. Theory and Research in Social Education, 34 (1), 34-57.

Lee, P.J. (1984) 'Historical imagination'. In Dickinson, A.K., Lee, P.J. and Rogers, P.J. (eds) Learning History. London: Heinemann Educational, 85-116.

Lee, P. and Ashby, R. (2001) 'Empathy, perspective taking, and rational understanding'. In Davis, O.L., Yeager, E.A. and Foster, S.J. (eds) Historical Empathy and Perspective Taking in the Social Studies. Lanham, MD: Rowman and Littlefield, 21-50.

Lee, P., Dickinson, A. and Ashby, R. (1997) '"Just another emperor": Understanding action in the past'. International Journal of Educational Research, 27 (3), 233-44.

Lévesque, S. (2008) Thinking Historically: Educating students for the twenty-first century. Toronto: University of Toronto Press.

Megill, A. (1989) 'Recounting the past: "Description", explanation, and narrative in historiography'. American Historical Review, 94 (3), 627-53.

Nilsen, A.P. (2016) 'Navigating windows into past human minds: A framework of shifting selves in historical perspective taking'. Journal of the Learning Sciences, 25 (3), 372-410.

Phillips, M.S. (2004) 'History, memory, and historical distance'. In Seixas, P. (ed.) Theorizing Historical Consciousness. Toronto: University of Toronto Press, 86-102.

Rantala, J. (2011) 'Assessing historical empathy through simulation: How do Finnish teacher students achieve contextual historical empathy?'. Nordidactica, 1, 58-76.

Rantala, J., Manninen, M. and Van den Berg, M. (2016) 'Stepping into other people's shoes proves to be a difficult task for high school students: Assessing historical empathy through simulation exercise'. Journal of Curriculum Studies, 48 (3), 323-45.

Seixas, P. and Morton, T. (2013) The Big Six Historical Thinking Concepts. Toronto: Nelson Education.

Shemilt, D. (1984) 'Beauty and the philosopher: Empathy in history and classroom'. In Dickinson, A.K., Lee, P.J. and Rogers, P.J. (eds) Learning History. London: Heinemann Educational, 39-84.

Skinner, Q. (1975) 'Hermeneutics and the role of history'. New Literary History, 7 (1), $209-32$.

Stockley, D. (1983) 'Empathetic reconstruction in history and history teaching'. History and Theory, $22(4), 50-65$.

Tully, J. (1988) Meaning and Context: Quentin Skinner and his critics. Princeton: Princeton University Press.

Virta, A. and Kouki, E. (2014) 'Dimensions of historical empathy in upper secondary students' essays'. Nordidactica, 2, 137-60.

Wineburg, S. (1999) 'Historical thinking and other unnatural acts'. Phi Delta Kappan, 80 (7), 488-99.

Yilmaz, K. (2007) 'Historical empathy and its implications for classroom practices in schools'. The History Teacher, 40 (3), 331-7. 